the fog was very dense, one's hair and overcoat also received a thick deposit of hoar-frost. It is noteworthy that in central London the fog, being exceedingly carbonaceous, and pungent with $\mathrm{SO}_{2}$, was too dry to deposit much ice or rime on the trees in Hyde Park, although the grass was thickly coated through terrestrial radiation. I have never seen much hoar-frost on the bare forest trees without fog, and I think that other observers will agree that the presence of fog is necessary for any great thickness to be formed. The dryness of the smoky town-fog as compared with the country-fog is well known, and this whether the temperature of the air is below the freezing point, as in the case in question, or above it. On the above dates at Northwood the fog dispersed for a couple of hours at mid-day, and the sun shone upon a fairyland in a sky of cloudless blue.

Northwood, Middlesex, February $\mathbf{I}$.

L. C. W. Bonacina.

\section{Germination of the Broad Bean Seed.}

THE text-book statements on the relation of the micropyle to the radicle are entirely wrong so far as I have been able to observe. If the testa be carefully removed it will be found to have two compartments, the larger one covering the cotyledons and the smaller sheathing the radicle. A fine bristle passed through the micropyle enters the cotyledon compartment. When the radicle emerges it does not pass through the micropyle, which is left intact, but the testa splits along two lines of weakness running from the tip of the radicle to its junction with the cotyledon stalks.

I noticed this about six years ago, and though I attach no importance to the mere fact, its interest is considerable from the point of view of nature-study in schools.

E. Herer Smith.

Episcopal Training College for Teachers, Dalry House, Orwell Place, Edinburgh, January 19.

\section{"Vestiges of the Natural History of Creation."}

IN "Vestiges of Creation," ninth edition, 185 I, p. I I 3 , it is stated that two independent investigators caused the production of "living insects" (Acarus crossii) by the prolonged action of a voitaic battery upon certain chemical solutions. The description is most matter-of-fact. The second experimenter seems to have sterilised his apparatus and solutions before use; yet it is said that the insects " were sometimes observed to go back to the fluid to feed, and occasionally they devoured each other." In Note 54 it is also stated that " after they have escaped from the solution they live in the neighbourhood, and readily breed."

I shall be much obliged if any reader can explain the above phenomenon, or say if the experiments have been repeated.

F. WrVille Thomson.

Caledonian United Service Club, Edinburgh,

January 28 .

\section{THE RADIUM INSTITUTE.}

THE announcement that, on the initiative of the King, a Radium Institute will shortly be opened in London is of the greatest interest to the man of science and to the physician. The institute is intended not only for research work, but also for curative purposes, and it will have an organised medical department. The whole of the funds necessary to build, equip, and maintain a new establishment are being provided by Sir Ernest Cassel and Lord Iveagh. We are reminded that Lord Iveagh gave the munificent sum of $250,000 l$. to endow the Lister Institute of Preventive Medicine, so that his name will now be associated gratefully with two great endowments of science. The committee of the institute will consist of Sir Frederick Treves, Bart., G.C.V.O., C.B. (chairman), Sir William Ramsay, K.C.B., F.R.S., Sir J. J. Thomson, F.R.S., the Hon. R. J. Strutt, F.R.S., Sir Lauder Brunton, Bart., F.R.S., Sir Malcolm
Morris, K.C.V.O., and two other members, one each to be nominated by Sir Ernest Cassel and Lord Iveagh.

The interest which the King is exhibiting in the inauguration of a scientific institution for further research work with radium, so that its powers may be utilised for the amelioration of human suffering, has led to the publication in the Press of the useful purposes to which radium may be put, and the inauguration of the Radium Institute will provide another example of the supreme importance to mankind of research work in science. The difficulty hitherto has been that so little of this remarkable body has been available for research. The trouble has been a financial one. Not long ago gocd specimens of radium bromide were obtainable for $5 l$. per milligramme, but recently the price has reached $16 l$. to $18 l$. per milligramme. It is obvious that in any case an enormous expenditure is required before a sufficiency can be obtained adequate for an institute, for the investigation of the properties of radium and its application for the treatment of disease. The necessary funds having now been provided, it will be possible to study radium from many points of view.

Radium is the most interesting of a group of bodies characterised by the property of spontaneously emitting radiations capable of passing through plates of metal or other substances impermeable to light. In 1896 , Becquerel found that uranium compounds and the metal itself give off rays which cause changes in a photographic plate even when passed through thin plates of metal. Uranium was isolated from pitchblende.so long ago as 1789 by Klapworth, and a little more than a hundred years later, in $1898, M$. and Mme. Curie discovered that certain varieties of this mineral possess greater radioactivity than could be accounted for by the uranium they contained. They were led to investigate these forms of pitchblende, and succeeded in isolating two new elements, polonium and radium.

The discovery of radium and its investigation have opened up enormous fields of research, and the following brief account of what has been done will suggest the possibilities before the Radium Institute, especially if a considerable quantity of the element can be under investigation.

Radium gives off three kinds of rays, respectively called $\alpha, \beta, \gamma$ rays, which have various properties. The $\alpha$ rays are identical with the radiations of high velocity, carrying a positive charge of electricity, which are projected through a perforation in the kathode of a Crookes's tube. They have been called "canal rays " by Goldstein, and have been investigated particularly by Wien. They travel in the opposite direction to the current through the tube, and have the power of ionising gases. The $\beta$ rays consist of negative particles, identical with the rays which are given off from the kathode and called " kathode rays." They have a velocity equal to that of light, and can be deviated by a magnetic field. The $\gamma$ rays are similar to the X-rays. They are not deflected by a magnetic field.

These rays have different powers of penetration. This is estimated by interposing layers of aluminium. The $\alpha$ rays have the least penetrative power; according to Rutherford, they may be taken as unity, the $\beta$ rays as of a penetrative power of IOo, and the $\gamma$ rays as of a penetrative power of 10,000. Practically the rays may be filtered by interposing layers of aluminium and lead. For instance, both the $\alpha$ and $\beta$ rays are completely absorbed by a layer of lead only one centimetre thick, but the $\gamma$ rays will pass through a layer of lead an inch thick. They are more penetrating than the X-rays. 